\title{
Efficacy of oral iron therapy in geophagic women with iron deficiency anaemia residing in Botshabelo, South Africa
}

\author{
LF Mogongoa \\ Department of Health Sciences, Faculty of Health Sciences, Central University of Technology, South Africa \\ Corresponding author, email: tpmogongwa@gmail.com
}

\begin{abstract}
Background: Iron deficiency anaemia is the most commonly encountered form of anaemia in females worldwide. This form of anaemia is, amongst others, associated with geophagia that is defined as the consumption of soil. The two main reasons for the association of geophagia with anaemia are that soil is thought to supplement mineral deficiency and geophagia is seen as a symptom of the anaemia. However, it is hypothesised that soil consumption interferes with iron absorption instead of supplementing it. The first line of therapy for iron deficiency anaemia is oral iron. Therefore, if soil consumption interferes with iron absorption it could interfere with oral iron therapy leading to patients being burdened with symptoms of anaemia as treatment is not effective. The aim of the study was to evaluate the efficacy of oral iron therapy in female participants afflicted with iron deficiency anaemia associated with geophagia.
\end{abstract}

Methods: In this prospective randomised intervention study, 84 geophagic women with iron deficiency anaemia were divided into two groups. One group continued with soil consumption while the other stopped consumption. Oral iron therapy was administered for ten weeks at increasing therapy doses for both groups. Red cell and iron study parameters were evaluated at different time intervals to ascertain the efficacy of iron replacement therapy.

Results: The group that stopped soil consumption showed a statistically significant change in haemoglobin $(9.4$ to $10.0 \mathrm{~g} / \mathrm{dL}$, $p=0.029$ ), mean corpuscular volume ( 73.6 to $75.7 \mathrm{f})$, mean corpuscular haemoglobin ( 23.7 to $24.6 \mathrm{pg})$, serum iron ( 22.5 to $28 \mu \mathrm{g} / \mathrm{dL}$, $p<0.001$, transferrin saturation ( 4.8 to $6.9 \%, p<0.001$ ) and total iron-binding capacity (467 to $441 \mu \mathrm{g} / \mathrm{L}, p=0.001$ ). These findings were contrary to the group that continued with consumption, where the statistical changes were only observed for the iron study parameters (serum iron: 21 to $28 \mu \mathrm{g} / \mathrm{dL}, p=0.038$; transferrin saturation: 4.3 to $6.9 \%, p=0.011$; total iron-binding capacity: 496 to $421 \mu \mathrm{g} / \mathrm{L}, p=0.002$ ). Nevertheless, the changes for both groups were clinically insignificant. Oral iron therapy did not correct the anaemia in geophagic females of both groups, this could be explained by two hypotheses where soil affected the gastrointestinal lining and soil directly interfered with therapy iron absorption. This is evidenced by the group that continued with consumption showing fewer changes than the group that abstained from soil consumption. These results were consistent with a case study where oral iron therapy was implemented.

Conclusion: Oral iron therapy was not effective in geophagia cases of iron deficiency anaemia.

Keywords: oral iron therapy, ferrimed, ferritin, geophagia, haemoglobin, transferrin saturation

\section{Introduction}

The deliberate consumption of soil, also known as geophagia, is mostly seen as a practice of marginal oddity. However, the practice is found throughout history. ${ }^{1}$ It is observed in many individuals and it has a peculiar multifactorial origin. ${ }^{2-9}$ Geophagia is derived from the Greek words geo- meaning earth and phagia- meaning eat. ${ }^{10}$ Consequently, geophagia can be described as the deliberate habitual consumption of soil/clay that is considered developmentally inappropriate. ${ }^{11-13}$ In order for persons to be diagnosed as geophagic, they must have consumed earthly substances continuously for more than one month. ${ }^{14}$ Geophagic practice has been described worldwide and it is widespread. ${ }^{15,15-27}$ From a plethora of studies, the percentage of people practising geophagia has been estimated to be anything from $5 \%$ to $85 \%$, depending on the specific studied population. ${ }^{28-32}$ The challenge for the current study was the paucity of information on the exact prevalence of geophagia on the study's target population, non-pregnant females. Moreover, it has been postulated that geophagia is more prevalent in subSaharan Africa. ${ }^{32-33}$ Geophagia has been reported among women and children in southern Africa ${ }^{5}$ particularly in South Africa. ${ }^{25,27,34}$ It is also said to be more common in people of African descent, ${ }^{32}$ especially women with iron deficiency anaemia. ${ }^{7,8,27-30,35,36}$

Iron deficiency anaemia (IDA) is the most common cause of anaemia worldwide. ${ }^{37-39}$ Globally, over two billion people are affected by iron deficiency. ${ }^{40}$ Furthermore, in the high-risk group composed of childbearing age females, a prevalence of $30 \%$ for IDA is noted for non-industrialised countries. ${ }^{40}$ An overall estimate of between $15-20 \%$ for anaemia and $7-15 \%$ for IDA in non-pregnant women was reported by various studies conducted in South Africa. ${ }^{41-44}$ IDA results when the net balance of iron absorption and loss is tilted towards iron loss. IDA in association with geophagia is commonly encountered in women of childbearing age as a result of menstrual blood loss 
and pregnancy secondary to supply of iron to the developing foetus. ${ }^{39-39,45}$ Consequently, the study population was composed of non-pregnant geophagic females. IDA affects the person by decreasing the delivery of oxygen to tissue, in addition causing restless legs syndrome, infertility, cognitive impairment, retarded growth development in children and low-birthweight. ${ }^{46-52}$ These factors lead to decreased productivity and quality of life. IDA can also affect the functioning of enzymes that contain iron causing cell abnormalities like hair thinning and diminished cellmediated immunity. ${ }^{53}$

There is evidence that geophagia and IDA are linked. $7,8,27-30,35,36$ The two main reasons for the association rest on two theories depending on the discipline. Geophagia is seen as an adaptive behaviour to obtain minerals that are deficient in the body. However, in the haematology circles geophagia (pica) is seen as a symptom of IDA. Although soil is seen as a means of mineral supplementation, there is contradictory in vitro evidence about the availability of iron in soil. Some authors hypothesise that soil might remove dietary iron ${ }^{11,35,53-56}$ and others postulating supplementation ${ }^{33,57-61}$ of dietary iron. The standard treatment of IDA is with an oral iron preparation to correct the anaemia and replenish the iron stores. ${ }^{36,39,45}$ The expected response to oral iron is usually an increase in haemoglobin by roughly $2 \mathrm{~g} / \mathrm{dl}$ within three weeks. ${ }^{38}$ If soil reduces iron bioavailability, then oral iron therapy might not be effective. In addition to the contradictory evidence, the paucity of studies performed on non-pregnant women and studies focusing on the treatment of IDA in geophagia necessitated this study. To unpack this conundrum a study was designed to investigate which theory about soil could be correct, especially when dealing with an in vivo human model. The aim of the study was to evaluate the efficacy of oral iron for treatment of iron deficiency anaemia in geophagic females, using red blood cell and iron parameters for evaluation.

\section{Materials and methods}

In this randomised single treatment intervention study, 84 nonpregnant geophagic Botshabelo women with mild to moderate IDA were selected to participate in the study. Botshabelo is situated 45 kilometres east of Bloemfontein, the capital city of Free State province, South Africa. This study's proposal was submitted to and approved by the Health Sciences Research Ethics Committee of the University of the Free State, reference number: ETOVS 17/2014. During recruitment, informed consent and family support for participants was sought by giving participants a week to think about their participation and consult with family. From the 320 recruited participants only 84 met the inclusion criteria. The inclusion criteria were as follows: no pregnant or lactating women, haemoglobin $<10.5 \mathrm{~g} / \mathrm{dl}$, ferritin $<15 \mu \mathrm{g} / \mathrm{L},>18$ years of age, participants should have stayed in Botshabelo for at least six months and consumed soil regularly for a month. The sample size was calculated with OpenEpi version 3, based on an effect of 30\% for the haemoglobin results. The average calculated sample size was 77 participants for the three sample size calculation methods. ${ }^{62}$
The participants were randomised into two groups and received oral iron therapy. Group $A(n=45)$ abstained from soil consumption and group $B(n=39)$ continued with soil consumption throughout the study period. The rationale for two groups was to indirectly evaluate the effect of soil on iron therapy absorption, that was to observe if stopping consumption of soil would have facilitated iron absorption over the study period. The participants received oral iron therapy over a ten-week period, at a concentration of between 100 and $200 \mathrm{mg}$ elementary iron a day. From baseline and for the first four weeks, all participants consumed one chewable tablet a day equivalent to $100 \mathrm{mg}$ elementary iron. At week four, one capsule was added to the regimen - resulting in a total of $150 \mathrm{mg}$ elementary iron. At week seven, a second capsule was added to the regimen giving a total of $200 \mathrm{mg}$ elementary iron per day. Therapy of IDA is recommended at 100 to $200 \mathrm{mg}$ of elementary iron. ${ }^{63}$ Ferrimed $^{\circledR}$ D.S. Chewable Tablets and Ferrimed ${ }^{\circledR}$ Capsules manufactured by Takeda, on behalf of Vifor, were utilised for therapy. ${ }^{64}$ The chewable tablet contained $100 \mathrm{mg}$ elementary iron as iron (III)-hydroxide polymaltose complex. Contrary to the chewable tablet, each capsule was composed of $50 \mathrm{mg}$ elementary iron as iron (III)-hydroxide polymaltose complex plus $150 \mu \mathrm{g}$ folic acid..$^{64}$ The total elementary iron dose per participant for ten weeks was $10.15 \mathrm{~g}$. The reason for product selection was because of a palatable taste and the product is stated to have fewer sideeffects, thus decreasing the odds of non-compliance or drop-out. Side-effects of oral therapy are dose-dependent, and in addition, adverse events can result in noncompliance of up to $50 \%$ of patients. ${ }^{65}$ Therefore, the first week was also deemed as a runin phase to acclimatise participants in taking study medication and to manage the side-effects that may have been encountered secondary to medication.

Two methods were utilised to assess compliance: pill count and questionnaire. For pill count, participants were given a different number of pills and they were required to present the excess number at a subsequent visit for counting. In so doing, an indication of compliance was 'semi'-obtained if the pills added up to the count that was issued at the beginning of the treatment period under review. ${ }^{66}$ For the questionnaire method of assessing compliance, data was captured on the side-effects questionnaire. ${ }^{67}$ The participants were asked to indicate if they had missed doses and the research team emphasised that missing a dose did not disqualify the participant but would assist the team in understanding anomalous results. Over time a good trust relationship was built with the participants. The data from both methods were combined to obtain an estimated compliance, as both methods allowed, based on their shortcomings. Compliance was calculated for each participant at all visitation periods, namely week 1, 4, 5, 7, and 10 .

The procedures and investigations that were undertaken during the study to assess the efficacy of therapy are summarised in Figure 1. The participants were exposed to oral iron therapy while being followed up at different time intervals. In total, six participants were lost to follow-up throughout the study, two from Group A and four from Group B. Blood was drawn at baseline, 


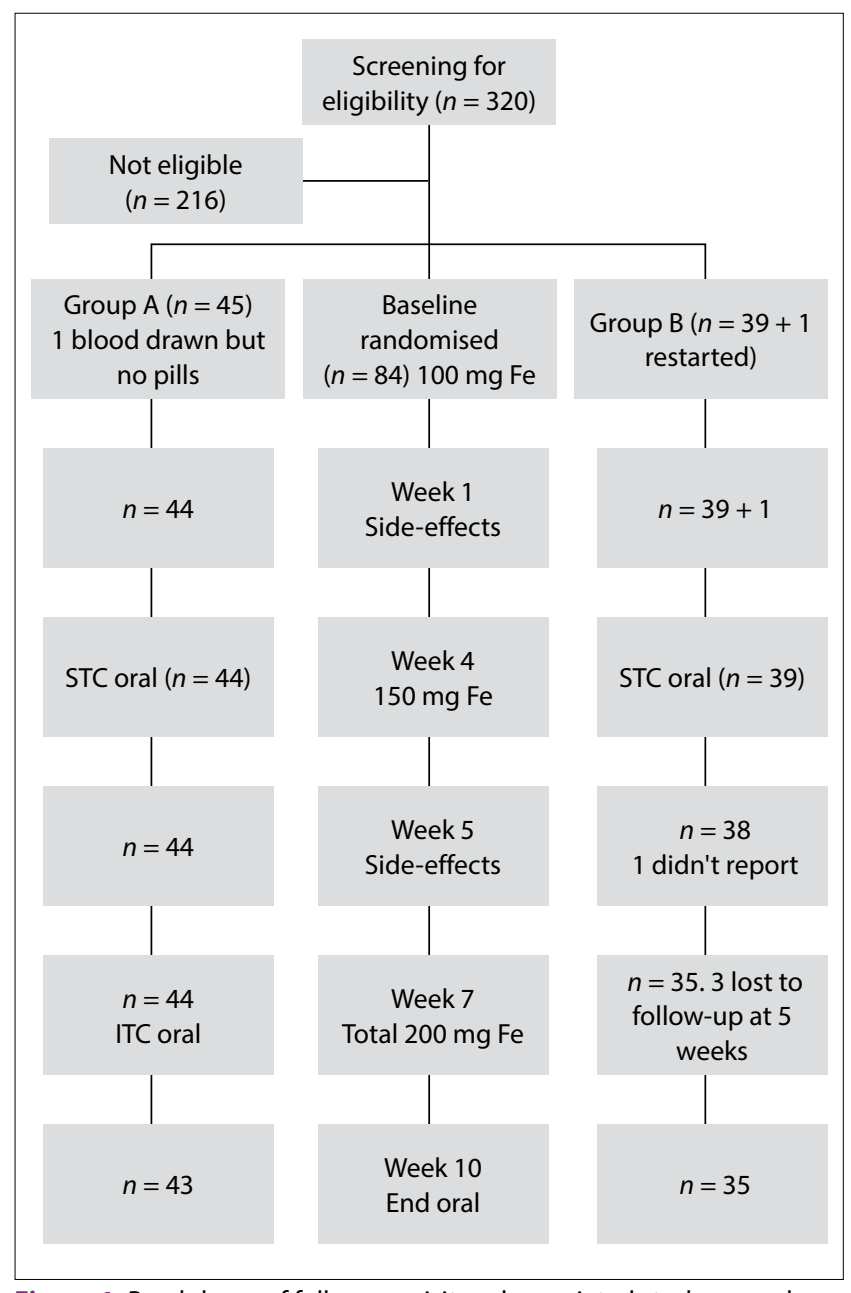

Figure 1: Breakdown of follow-up visit and associated study procedure ITC - intermediate changes; STC -- short-term changes

week 4 (short-term changes - STC), week 7 (intermediate changes - ITC) and week 10 (end of oral therapy). EDTA and clotted blood specimens were obtained to detect pregnancy, inflammation, assess haematology and clinical chemistry changes associated with IDA correction at each visit; except weeks 1 and 5 which were utilised to assess the side-effects related to the medication. The side-effects questionnaire, that was administered at all study visits, also assessed the geophagia status of every participant. To remain in group $A$, a threshold of $5 \%$ consumption was set and no participant reached this threshold. Furthermore, selected minerals, liver and kidney screening tests were also performed at the beginning and end of the study; the purpose was to assess the general health of the participants (please note that this data is not part of the scope of this article thus it is not presented).

Full blood count was performed at all visits, within four hours of blood collection; using the ABX Pentra $60^{\oplus} .68$ The instrument utilised spectrophotometry; double hydrodynamic sleeving coupled with cytochemistry; current impedance changes and measuring of transmitted light; to measure the different parameters of the full blood count. ${ }^{68}$ Iron study analyses were performed using the Siemens Dimension ${ }^{\circledR}$ autoanalyser. ${ }^{69}$ The principles of the different tests that were undertaken ranged from immunoturbidimetry, turbimetric, Ferene and Ferene direct. ${ }^{69}$
The statistical analyses were performed utilising the SPSS ${ }^{\circledR}$ program. Data were summarised as means and standard deviation for each measured variable, with a normal distribution. Normality was ascertained by performing the Shapiro-Wilk test and histogram evaluation. In addition, Levene's test for equality of variances was also undertaken to ascertain the $p$-value that should be reported. Paired sample T-test analysis was utilised to compare two study periods of the same group. Independent T-test was employed when comparing different groups. The differences among the data sets within a treatment (baseline, short-term, intermediate-term and end of treatment) group were analysed by repeated-measures analysis of variance (ANOVA). To ascertain sphericity, the Mauchly's test was performed. If the sphericity assumption was not met, then a Greenhouse-Geisser correction was determined. However, data from the variables that produce a non-Gaussian distribution were summarised as median and interquartile range. The difference among follow-up time periods and the different treatment groups were compared utilising the Friedman test and Wilcoxon signed-rank test, respectively. The post-hoc test employed for the Friedman test was the paired Wilcoxon signed-rank test.

\section{Results}

The total calculated compliance for the combination of both therapy forms, chewable and capsule [median (IQR)], was 95\% (90-99\%); 98\% (92-100\%) and 92\% (85-98\%) for the entire study population, group $A$ and $B$, respectively. There was a significant difference $(p=0.031)$ between group $A$ (median $=98 \%)$ and group $B$ (median $=92 \%$ ), indicating that group A participants were more compliant than group B. Furthermore, the calculated compliance for the different forms of therapy, chewables ( $p=0.062)$ and capsules $(p=0.404)$ separately, for group A versus $B$ were not significantly different.

\section{Baseline results of the entire study population and study groups post-randomisation}

The mean age was 32 years with a range of 18-51 years, with $25 \%$ of participants being below 24 years and $25 \%$ being above 40 years, as captured in Table I. Mean body mass index (BMI) was just above the reference range; this indicated that approximately half of the participants were overweight $\left(25-29.9 \mathrm{~kg} / \mathrm{m}^{2}\right)$. Less than $16 \%$ of participants were considered underweight $\left(<18.5 \mathrm{~kg} / \mathrm{m}^{2}\right)$ based on the minimum $\left(17.3 \mathrm{~kg} / \mathrm{m}^{2}\right)$ and mean minus standard deviation $\left(19.33 \mathrm{~kg} / \mathrm{m}^{2}\right)$, whereas less than $25 \%$ fell in the obese category $\left(>30 \mathrm{~kg} / \mathrm{m}^{2}\right)$ based on the $75^{\text {th }}$ percentile $\left(29.5 \mathrm{~kg} / \mathrm{m}^{2}\right)$. The BMI data was supported by the waist-hip ratio (WHR) which showed a similar trend. The mean WHR of 0.83 indicated that more than $50 \%$ of participants were within the moderate risk category (0.81-0.85). Additionally, greater than $25 \%$ were within the high-risk category $(>0.85)$ based on the $75^{\text {th }}$ percentile of 0.88 . The blood pressure measurements of approximately $25 \%$ of participants were above the reference range, as witnessed by the $75^{\text {th }}$ percentile of both systolic $(142.3 \mathrm{mmHg})$ and diastolic $(89.3 \mathrm{mmHg})$ measurements. Furthermore, less than $16 \%$ of participants had systolic and diastolic blood pressure of more than $156 \mathrm{mmHg}$ and $104 \mathrm{mmHg}$ based on mean plus standard deviation, respectively. 
Table I: Baseline anthropometric and general health indicators of the entire study population

\begin{tabular}{lccc}
\hline \multicolumn{1}{c}{ VARIABLE } & $\begin{array}{c}\text { Reference } \\
\text { ranges }\end{array}$ & $\begin{array}{c}\mathbf{X} \pm \mathbf{S D} \\
(\mathbf{m i n}-\mathbf{m a x})\end{array}$ & $\begin{array}{c}\text { Med } \\
{[\mathbf{I Q R}]}\end{array}$ \\
\hline Age (years) & & $\begin{array}{c}32.3 \pm 9.3 \\
(18.0-51.0)\end{array}$ & $\begin{array}{c}36.0 \\
{[24.0-40.0]}\end{array}$ \\
& & $25.4 \pm 6.1$ & 24.2 \\
$\mathrm{BMI}\left(\mathrm{kg} / \mathrm{m}^{2}\right)$ & $18.5-24.9$ & $(17.3-44.3)$ & {$[20.3-29.5]$} \\
& & $0.83 \pm 0.07$ & 0.83 \\
WHR & $\leq 0.80$ & $(0.69-1.11)$ & {$[0.76-0.88]$} \\
& & $131.4 \pm 24.9$ & 122.0 \\
$\mathrm{SBP}(\mathrm{mmHg})$ & $125 \pm 13.6$ & $(82.0-205.0)$ & {$[116.0-142.3]$} \\
& & $85.0 \pm 18.7$ & 84.0 \\
DBP $(\mathrm{mmHg})$ & $78 \pm 9.9$ & $(55.0-144.0)$ & {$[71.8-89.3]$} \\
\hline
\end{tabular}

$\mathrm{BMI}$ - body mass index; DBP - diastolic blood pressure; IQR - interquartile range; Max maximum; Med - median; Min - minimum; SBP - systolic blood pressure; SD - standard deviation; WHR - waist:hip ratio; $\mathrm{X}$ - mean

At baseline, the participants presented with a hypochromic microcyticanaemiabased on the means of meancell haemoglobin (23.2 pg), mean cell volume (72.9 fl) and haemoglobin $(9.2 \mathrm{~g} / \mathrm{dl})$ which were below the reference ranges, as expressed in Table II. The serum iron, ferritin and transferrin saturation (TSAT) level of more than $84 \%$, calculated from the mean plus standard deviation ( $45.1 \mu \mathrm{g} / \mathrm{dL}, 14 \mu \mathrm{g} / \mathrm{dL}$ and $10 \%$, respectively), had concentrations below the reference ranges as captured in Table II. Ferritin level signified that those participants with levels below range met the inclusion criteria of the study which was ferritin < $15 \mu \mathrm{g} / \mathrm{L}$. Group B's mean values were lower than those of group $A$, potentially signifying a more severe IDA in this group. However, there were no statistically significant changes between the two groups as evidenced by the independent samples t-test $p$ values of $>0.05$. This finding signified that randomisation was effective and the difference observed was not important.

\section{Mean changes for the entire population throughout the study period}

Mean changes of haemoglobin concentration $(\mathrm{Hb})$, mean cell volume (MCV) and mean cell haemoglobin $(\mathrm{MCH})$ indicated an increasing pattern from baseline to the end of oral therapy, as illustrated in Table III. However, this increase was not statistically significant because the repeated measures ANOVA revealed $p$ values $>0.05$ and clinically insignificant since the mean results did not correct into the reference ranges. In addition, an increase of $2 \mathrm{~g} / \mathrm{dl}$ in $\mathrm{Hb}$ over the ten weeks was observed in only $6.4 \%$ (5/78) participants. However, repeated measures ANOVA with Greenhouse-Geisser correction determined that there were statistically significant decreases for total iron binding capacity (TIBC) between different time periods of oral iron therapy $F(2.31,168.74)=2.96, p=0.047$. The means of TIBC at all followup visits remained above the reference range. Furthermore, there were significant differences for serum iron, ferritin and TSAT between the different oral iron therapy follow-up periods, $X^{2}=23.132, p<0.001 ; x 2=9.109, p=0.028$ and $x 2=15.580$, $p<0.001$, respectively. Even though the medians of serum iron, ferritin and TIBC increased from baseline, no parameter improved to such an extent that the values were within the reference values for this population group, as illuminated in Table III.

\section{Mean changes for each study group throughout the study period}

Repeated measures ANOVA with Greenhouse-Geisser correction determined that there were statistically significant increases in haemoglobin, MCV and MCH from baseline to week 10; $F(1.42$, $62.56)=4.31, p=0.029 ; \mathrm{F}(1.12,49.23)=8.19, p=0.005$ and $\mathrm{F}(1.23$,

Table II: Baseline results for entire population, group A, B and A vs B (T test $p$-value)

\begin{tabular}{|c|c|c|c|c|c|}
\hline Variable & Reference range ${ }^{70}$ & Entire population & Group A mean \pm SD & Group B mean \pm SD & $p$-value (group A vs B) \\
\hline $\mathrm{Hb}(\mathrm{g} / \mathrm{dl})$ & $11.5-15.0$ & $9.2 \pm 1.5$ & $9.4 \pm 1.5$ & $9.0 \pm 1.4$ & 0.233 \\
\hline $\mathrm{MCV}(\mathrm{fl})$ & $81-100$ & $72.9 \pm 8.6$ & $73.6 \pm 8.6$ & $72.0 \pm 8.7$ & 0.395 \\
\hline $\mathrm{MCH}(\mathrm{g} / \mathrm{dl})$ & $27-32$ & $23.2 \pm 3.5$ & $23.7 \pm 3.4$ & $22.7 \pm 3.6$ & 0.198 \\
\hline $\mathrm{SFe}(\mu \mathrm{g} / \mathrm{dL})$ & $56-168$ & $26.1 \pm 19$ & $28.1 \pm 22.3$ & $24.1 \pm 14.8$ & 0.409 \\
\hline Ferritin $(\mu \mathrm{g} / \mathrm{L})$ & $15-200$ & $8.0 \pm 6.0$ & $9.3 \pm 7.7$ & $6.7 \pm 3.1$ & 0.057 \\
\hline TIBC $(\mu \mathrm{g} / \mathrm{L})$ & $250-400$ & $483 \pm 77.6$ & $474.4 \pm 80$ & $495.3 \pm 75.3$ & 0.225 \\
\hline TSAT (\%) & $16-50$ & $5.6 \pm 4.3$ & $6.2 \pm 5.4$ & $4.9 \pm 2.8$ & 0.211 \\
\hline
\end{tabular}

Ferr - ferritin; $\mathrm{Hb}$ - haemoglobin; MCH - mean cell haemoglobin; MCV - mean cell volume; SD - standard deviation; S Fe - serum iron; TIBC - total iron-binding capacity; TSAT - transferrin saturation

Table III: Entire population's results at all follow-up visits

\begin{tabular}{|c|c|c|c|c|c|}
\hline Variable & Baseline mean (IQR) & STC (W4) mean \pm SD & ITC (W7) & End (W10) & ANOVA $p$-value \\
\hline $\mathrm{Hb}(\mathrm{g} / \mathrm{dl})$ & $9.2 \pm 1.5^{*}$ & $9.5 \pm 1.6$ & $9.6 \pm 1.8$ & $9.7 \pm 1.8^{*}$ & 0.129 \\
\hline MCV (fl) & $72.8 \pm 8.9^{*}$ & $72.7 \pm 8.7$ & $73.6 \pm 9.1$ & $74.4 \pm 9.4^{*}$ & 0.307 \\
\hline $\mathrm{MCH}(\mathrm{g} / \mathrm{dl})$ & $23.2 \pm 3.6^{*}$ & $23.3 \pm 3.7$ & $23.6 \pm 3.8$ & $23.9 \pm 4.0^{*}$ & 0.323 \\
\hline $\mathrm{SFe}(\mu \mathrm{g} / \mathrm{dL})$ & $22(16-27)^{* !}$ & $22(17-31)$ & $28.5(19-41)^{!}$ & $28(19-40)^{*}$ & $<0.001$ \\
\hline Ferr $(\mu \mathrm{g} / \mathrm{L})$ & $6.5(4-10)^{* \$}$ & $7(4-11)$ & $7(5-13)^{*}$ & $8(5-12)^{5}$ & 0.028 \\
\hline TIBC $(\mu \mathrm{g} / \mathrm{L})$ & $483 \pm 77.6^{*}$ & $497 \pm 96.4$ & $436 \pm 86.3^{*}$ & $436.5 \pm 65.4^{*}$ & $<0.001$ \\
\hline TSAT (\%) & $4.8(3.4-6.1)^{5 \&}$ & $4.9(3.4-6.9)^{* !}$ & $6.2(4.4-9.3)^{8 !}$ & $6.9(4.3-9.6)^{* \&}$ & $<0.001$ \\
\hline
\end{tabular}

Ferr - ferritin; $\mathrm{Hb}$ - haemoglobin; IQR - interquartile range; ITC - intermediate change; MCH - mean cell haemoglobin; MCV - mean cell volume; SD - standard deviation; S Fe - serum iron; STC short-term changes; TIBC - total iron-binding capacity; TSAT - transferrin saturation; W4, 7, 10 - week 4, 7, 10.

*\&s! - means/medians with a similar special character signify statistically significant change between the time periods. 
Table IV: Mean changes for group A at different follow up visits

\begin{tabular}{lccccc}
\hline Variable & Baseline mean (IQR) & STC (W4) mean \pm SD & ITC (W7) & End (W10) & ANOVA p-value \\
\hline $\mathrm{Hb}(\mathrm{g} / \mathrm{dl})$ & $9.4 \pm 1.5^{*}$ & $9.7 \pm 1.6$ & $9.9 \pm 1.8$ & $10.0 \pm 1.7^{*}$ & 0.029 \\
$\mathrm{MCV}(\mathrm{fl})$ & $73.6 \pm 8.6^{*}$ & $74.2 \pm 8.4$ & $75.3 \pm 8.9$ & $75.7 \pm 8.5^{*}$ & 0.005 \\
$\mathrm{MCH}(\mathrm{g} / \mathrm{dl})$ & $23.7 \pm 3.4^{*}$ & $24 \pm 3.5$ & $24.3 \pm 3.5$ & $24.6 \pm 3.7^{*}$ & 0.014 \\
$\mathrm{~S} \mathrm{Fe}(\mu \mathrm{g} / \mathrm{dL})$ & $22.5(17-28)^{* 5}$ & $24(18-31)^{!}$ & $29(21-41)^{* !}$ & $28(20-40)^{5}$ & $<0.001$ \\
\hline Ferr $(\mu \mathrm{g} / \mathrm{L})$ & $7(4-12.5)$ & $8(5-16)$ & $8(5-15)$ & $7(5-14)$ & 0.038 \\
$\mathrm{TIBC}(\mu \mathrm{g} / \mathrm{L})$ & $467(432-516)^{* \& !}$ & $441(411-484)^{!}$ & $430(404-481)^{\&}$ & $441(389-477)^{*}$ & 0.001 \\
$\mathrm{TSAT}(\%)$ & $4.8(3.5-6.3)^{* !}$ & $5.1(3.5-8.1)$ & $6.9(4.9-10)^{!}$ & $6.9(4.3-10.7)^{*}$ & $<0.001$ \\
\hline
\end{tabular}

Ferr - ferritin; Hb - haemoglobin; IQR - interquartile range; ITC - intermediate change; MCH - mean cell haemoglobin; MCV - mean cell volume; SD - standard deviation; S Fe - serum iron; STC short-term changes; TIBC - total iron-binding capacity; TSAT - transferrin saturation; W4, 7, 10 - week 4, 7, 10

* $\& \$$ ! - means/medians with a similar special character signify statistically significant change between the time periods.

49.65) $=6.12, p=0.014$, respectively for group $\mathrm{A}$, as depicted in Table IV. Additionally, an increase of $2 \mathrm{~g} / \mathrm{dl}$ in $\mathrm{Hb}$ over the ten weeks was observed in $9.3 \%$ (4/43) participants. Furthermore, there were significant differences for serum iron, ferritin, TIBC and TSAT between the different follow-up periods, $X 2=81.707$, $p<0.001 ; X^{2}=8.402, p=0.038 ; X^{2}=15.642, p=0.001$ and $X^{2}=$ $21.900, p<0.001$, respectively. Post-hoc analysis with Wilcoxon signed-rank tests was conducted for ferritin, the difference between baseline and week 7 did not meet $(p=0.024)$ the Bonferroni correction significance level of $p<0.008$. The medians for ferritin were below the reference range for all time intervals. The medians of serum iron and TSAT increased from baseline to end of oral iron therapy. For TIBC, the medians dropped from baseline until ITC but increased at the end of oral iron therapy. However, the medians were still outside the reference ranges. Despite all the above-mentioned statistical changes in group $A$, none were clinically noteworthy.

Haemoglobin concentration of group $B$ revealed a significant change with the overall ANOVA $(p=0.042)$. However, the posthoc test did not reveal any significant change among the time periods. Furthermore, an increase of $2 \mathrm{~g} / \mathrm{dl}$ in $\mathrm{Hb}$ over the ten weeks was observed in one participant $(2.9 \%=1 / 35)$. The red cell parameters' means were below the reference range, as presented in Table V. Additionally, there were significant differences for serum iron, TIBC and TSAT between the different follow-up periods, $X^{2}=8.436, p=0.038 ; X^{2}=14.767, p=0.002$ and $X^{2}=17.233, p<0.001$, respectively. The medians of serum iron, ferritin and TSAT lingered below the reference range for all oral iron therapy visits as captured in Table V.
Group A showed significant changes with red cell indices and iron study parameters, contrary to group $B$ where the significant changes were only obtained with the iron study parameters. It must be noted that haemoglobin in group $B$ and ferritin for both groups did not show statistically significant changes. Most importantly, the changes in both groups were not clinically significant. One of the objectives of the study was to evaluate if the abstaining group would lead to a better response to oral iron therapy. Thus, factorial ANOVA analysis was undertaken to ascertain if belonging to a group made a difference. A factorial ANOVA with Greenhouse-Geisser correction determined no significant difference for all the parameters, because $p$ values were above 0.05 , signifying that belonging to a group did not offer any advantage.

\section{Discussion}

From the 320 screened participants only 84 met the inclusion criteria at a rate of $26 \%$ that was comparable to the odds ratio of 1.4-2.5 (95\% confidence interval) that a geophagic person would have IDA as reported previously. ${ }^{27}$ The drop-out rate was $7 \%(6 / 84)$ which was lower than what is expected for a comparable study, e.g. $18 \%{ }^{71}$ and $22 \% .^{72}$ The reasons were due to the process followed to obtain consent. Knowing where participants lived also enabled easy follow-up and this approach made participants more comfortable. Reasons for withdrawal of six participants were relocation, losing contact with participants and participants no longer interested in the study.

Compliance was much higher in this study (97\%) than other similar studies, e.g. $67 \%{ }^{73}$ and $50 \% .^{74}$ High compliance might be explained by the low number of side-effects encountered

Table V: Mean changes for group B at different follow-up visits

\begin{tabular}{lccccc}
\hline Variable & Baseline mean (IQR) & STC (W4) mean \pm SD & ITC (W7) & End (W10) & ANOVA $p$-value \\
\hline $\mathrm{Hb}(\mathrm{g} / \mathrm{dl})$ & $9.0 \pm 1.4$ & $9.3 \pm 1.5$ & $9.3 \pm 1.6$ & $9.3 \pm 1.8$ & 0.042 \\
$\mathrm{MCV}(\mathrm{fl})$ & $72.0 \pm 8.7$ & $71.4 \pm 8.7$ & $72.1 \pm 9.4$ & $72.6 \pm 9.8$ & 0.069 \\
$\mathrm{MCH}(\mathrm{g} / \mathrm{dl})$ & $22.7 \pm 3.6$ & $22.8 \pm 3.8$ & $23.0 \pm 4.0$ & $23.1 \pm 4.2$ & 0.073 \\
$\mathrm{~S} \mathrm{Fe}(\mu \mathrm{g} / \mathrm{dL})$ & $21(14-27)^{* !}$ & $21.5(17-39)^{5}$ & $24(17-41)^{* 5}$ & $28(19-39)^{!}$ & 0.038 \\
\hline Ferr $(\mu \mathrm{g} / \mathrm{L})$ & $6(5-8)$ & $6(4-8.5)$ & $6(5-9)$ & $8(4-10)$ & 0.261 \\
\hline $\mathrm{TIBC}(\mu \mathrm{g} / \mathrm{L})$ & $493(439-554)^{* !}$ & $483(436-546)$ & $434(399-486)^{8 !}$ & $421(394-496)^{!}$ & 0.002 \\
$\mathrm{TSAT}(\%)$ & $4.3(3.1-6.1)^{5 \&}$ & $4.8(3.3-6.6)^{*}$ & $5.9(3.9-9.0)^{\&}$ & $6.9(3.9-9.5)^{*}$ & 0.011 \\
\hline
\end{tabular}

Ferr - ferritin; $\mathrm{Hb}$ - haemoglobin; IQR - interquartile range; ITC - intermediate change; MCV - mean cell volume; MCH - mean cell haemoglobin; SD - standard deviation; S Fe - serum iron; STC short-term changes; TIBC - total iron-binding capacity; TSAT - transferrin saturation; W4, 7, 10 - week 4, 7, 10 
due to the type of oral preparation utilised, ${ }^{75}$ the individualised follow-up of participants at their own homes and the motivation of participants to quit the habit. There was no preference for either chewables or capsules based on the study group, even though group A had higher compliance rate than group B for the combined therapy form. However, the significant change of $A$ versus $B$ was not clinically noteworthy because the level of compliance for both groups was above the limit that is normally achieved. The age criteria for the study group was within the inclusion criteria and the study's age group was akin to other studies conducted in the Limpopo ${ }^{76}$ and KwaZulu Natal ${ }^{77}$ provinces, South Africa.

The sample population reflected the general population based on the lifestyle-related findings, namely hypertension and obesity. A quarter of the participants showed a tendency towards hypertension, with almost 16\% having stage 2 hypertension (> 160 systolic or $>100$ diastolic). This is comparable to the $24.4 \%$ found in other studies. ${ }^{78-81}$ Based on BMI and WHR, more than $50 \%$ of participants presented with a common but serious health condition in South Africa namely, obesity. The problem was even worse in $25 \%$ of participants as they were classified in the highrisk group. One of the theories of geophagia is its theoretical association with hunger. However, most of the participants were not malnourished but obese. The obesity in this case refutes the hunger theory.

The selection criteria were designed for choosing individuals with mild hypochromic microcytic anaemia and iron study indicators that are associated with IDA. Hence, the entire population data at baseline reflected that. Moreover, there were no significant changes in the full blood count parameters and iron studies indicators, thus the degree of IDA was akin in both groups at baseline. In addition, this finding signified that randomisation produced two similar groups. Therefore, changes observed after treatment were not due to differences between the groups themselves.

\section{Entire study population changes}

According to the repeated measures ANOVA there were significant differences for all three IDA related full blood count parameters for the entire study group. These differences were not of clinical importance as the expected response in $\mathrm{Hb}$ is an increase of $2 \mathrm{~g} / \mathrm{dl}$ in 3-4 weeks, $63,82,83$ the mean $\mathrm{Hb}$ increase was only $0.5 \mathrm{~g} / \mathrm{dl}$ over a ten-week period. The expected therapeutic response with iron therapy was an increase in serum iron, ferritin and TSAT. All these showed a significant increase especially at ITC and end of oral therapy. However, the response was not of clinical importance. TIBC was expected to decrease during iron therapy, and this was the case. However, TIBC was statistically significant for the same time period. Overall, these results signified that time and increased doses of oral iron did not have a significant impact on therapy outcome. In a case study, similar results were found where a female with geophagia and IDA did not respond to oral iron therapy. ${ }^{35}$ It must be noted that, according to the author's knowledge, there were no geophagia-IDA directed therapy studies performed. Therefore, further comparison with other studies was not feasible.

The reasons for the non-responsiveness to oral iron therapy could be due to any of the five below-mentioned hypotheses or a combination of them. ${ }^{11,35,53-56,84}$ Kaolinite or soil's constituents could have caused malabsorption of nutritional and treatment iron, thereby interfering with oral iron therapy. ${ }^{11,35}$ Alternatively soil directly interfered with iron absorption by coating to the absorptive surface of the gastrointestinal tract thereby interfering with the iron transport across the intestinal wall. ${ }^{11,54-56}$ Otherwise, soil due to its abrasive nature could have caused changes to the absorptive surface of the gastrointestinal tract, thus interfering with iron absorption. ${ }^{11,54-56}$ On the other hand, soil could have changed the $\mathrm{pH}$ of the gastrointestinal tract environment; $\mathrm{pH}$ plays an important role in inorganic iron absorption. ${ }^{11,56}$ Finally, the theory of daily iron supplementation resulting in increased hepcidin production that would inhibit iron absorption. ${ }^{53,84}$ Any of these theories could have been at play either alone or in combination, thus further studies are warranted.

\section{Mean changes for the group that abstained from soil consumption}

The red cell parameters $\mathrm{Hb}, \mathrm{MCV}$ and $\mathrm{MCH}$ showed a statistically but not clinically significant increase from baseline to end of oral therapy. TIBC decreased, serum iron and TSAT increased, although overall ANOVA for ferritin was significant, it did not reveal a significant difference in post-hoc analysis. These changes were as expected because they imply that the treatment was minimally successful, but the disappointing fact was that they were not clinically noteworthy. Due to the less than expected improvement on red cell parameters and iron studies, this implied that iron absorption was not optimal, possibly caused by changes to the gastrointestinal tract (GIT) lining. ${ }^{11,54-56}$ This leads to the conclusion that oral iron did not correct the red cell parameters of the abstain group sufficiently as the expected therapy outcomes were not encountered. Due to the participant not consuming soil, it can be implied that soil, due to its granular nature, could have caused changes to the GIT absorptive surface thus leading to a suboptimal response to oral iron therapy. However, the non-effectiveness of iron therapy could also be due to another confounding factor. ${ }^{84}$ It must be noted that chronic anaemia suppresses hepcidin production, ${ }^{11}$ thus daily iron supplementation may still be effective under these conditions. Furthermore, ten weeks might not be enough to revert these GIT changes to normal because of the lack of effective therapy observed in this study.

\section{Mean changes of the group that continued with soil consumption}

$\mathrm{Hb}$ concentration increased from baseline to STC and then remained the same for the rest of the visits. Serum iron and TSAT increased from baseline to STC, ITC and end of oral therapy, contrary to TIBC which decreased for the same time period. Implying that an increase in therapy iron concentration had a minor impact on iron study results. It must be noted that the changes were not clinically noteworthy indicating that iron 
therapy was not effective in this study group. Ferritin did not show significant change as expected because most iron that is absorbed is utilised for red cell synthesis, not diverted to storage. This could imply that soil interfered with iron absorption over and above the changes to the GIT lining postulated in group A. This supposition is supported by group $B$ not showing significant changes in the red cell parameters contrary to group A. Plus fewer participants in group $B$ achieved an increase of $2 \mathrm{~g} / \mathrm{dl}$ compared to group A.

The significant changes observed signified that some iron was absorbed, although it was not enough to produce a clinically substantial change in the monitored IDA parameters. Therefore, the effects of oral iron therapy were not as expected for treatment of IDA associated with geophagia and abstinence from soil did not show a marked improvement in the IDA parameters. These effects were assessed utilising both red cell and iron study parameters. These effects were observed despite acceptable compliance by participants. More importantly, iron therapy was still not effectively absorbed in the absence of soil in the GIT. This signifies that consumption of soil has a lasting effect of at least ten weeks on the GIT absorption surface resulting in iron malabsorption. Furthermore, data from this study suggest that soil directly interfered with therapy iron absorption and caused malabsorption on the GIT absorptive surface. Therefore, a clinical study investigating the effects of soil on the GIT lining by means of cell culture techniques ${ }^{56}$ or gastroscopy is warranted. Another study could also involve assessing the effect of geophagic soils on therapy iron bio-accessibility. ${ }^{85,86}$ Furthermore, a multi-centre study involving more participants and alternative day iron supplement is warranted.

\section{Conclusion}

In this study oral iron therapy was not effective for the correction of iron deficiency anaemia in geophagic Botshabelo females. These findings imply that the geophagic patient with IDA will carry an unwarranted burden of symptoms for a long time and this may even affect future pregnancy, especially because geophagia affects mostly females of childbearing age and anaemia is associated with low-birth weight. Furthermore, these females will be less productive thus not contributing as effectively to society through their career and have a decreased quality of life. Additionally, the healthcare system will carry the financial burden while ineffective treatment is administered, which places a large burden on an already resource-constrained health system. Therefore it is recommended that further local studies into geophagia-associated IDA are conducted to ascertain the true extent of geophagia nationally, the short- and long-term effects of geophagia on the GIT, the best treatment options for correcting the effects of geophagia on the GIT and how to reverse IDA if geophagia has caused irreversible damage to the GIT.

\section{Acknowledgements}

I acknowledge the research participants and the research team (Dr Jafta, Ms Raphuthing, Ms Shashane, Mr Ncoko and Ms Segalo) without whom the study would not have succeeded. In addition, critical reading by Mrs Wiese, Ms Raphuthing and Dr Brand.

\section{Funding declaration}

This work is based on a research supported in part by the National Research Foundation (NRF) of South Africa (Unique Grant No. 93970 \& 105787), the Central University of Technology, Free State (CUT) and the Department of Higher Education and Training (DHET) UCDP GRANT for the financial support. Any opinion, finding and conclusion or recommendation expressed in this material is that of the author; the NRF, DHET and CUT do not accept any liability in this regard.

\section{Conflict of interest}

Author declares no conflict of interest.

\section{Orcid}

LF Mogongoa (iD https://orcid.org/0000-0001-6378-033X

\section{References}

1. Woywodt A, Kiss A. Geophagia: the history of earth-eating. Journal of the Royal Society of Medicine. 2002;95:143-146. https://doi.org/10.1258/jrsm.95.3.143.

2. Eastwood M. Principles of human nutrition. London: Chapman and Hall; 1999.

3. Crane L. Would you like a little soil with that? MedHunters.com; 2004. Available from: http://www.medhunters.com/articles/wouldYouLikeALittleSoilWithThat. html.

4. Dreyer MJ, Chaushev PJ, Gledhill RF. Biochemical investigation of geophagia. Journal of the Royal Society of Medicine. 2004;97(1):48. https://doi.org/10.1177 1014107680409700125 .

5. Luoba Al, Geissler PW, Estambale B, et al. Geophagy among pregnant and lactating woman in Bondo District, Western Kenya. The Royal Society of Tropical Medicine and Hygiene. 2004;98(12):734-741. https://doi.org/10.1016/j. trstmh.2004.01.009.

6. Kondo DG, Sokol MS. Eating disorders in primary care. Postgraduate Medicine. 2006;119(3):59-65. https://doi.org/10.1080/00325481.2006.11446052.

7. Yao P. A case of geophagia. Proceedings of UCLA Healthcare; 2006;10:1-2.

8. Young SL, Khalfan SS, Farag TH, et al. Association of pica with anaemia and gastrointestinal distress among pregnant women in Zanzibar, Tanzania. The American Society of Tropical Medicine and Hygiene. 2010;83(1):144-151. https:// doi.org/10.4269/ajtmh.2010.09-0442.

9. Chen MH, Su TP, Chen YS, et al. Association between psychiatric disorders and iron deficiency anemia among children and adolescents: a nationwide population-based study. BMC Psychiatry. 2013;13:161. https://doi. org/10.1186/1471-244X-13-161.

10. Geophagy. (n.d.). Online Etymology Dictionary. Retrieved June 15, 2017 from Dictionary.com. Available from: http://www.dictionary.com/browse/geophagy.

11. Hooda PS, Henry CJK, Seyoum TA, Armstrong LDM, Fowler MB. The potential impact of soil ingestion on human mineral nutrition. Sciences of the Total Environment. 2004;333:75-87. https://doi.org/10.1016/j.scitotenv.2004.04.023.

12. Blinder BJ, Salama C. An update on pica prevalence, contributing causes, and treatment. Psychiatric Times. May 2008;25(6):66-73. Available from: https://www.psychiatrictimes.com/eating-disorders/ update-pica-prevalence-contributing-causes-and-treatment.

13. Barton JC, Barton JC, Bertoli LF. Pica associated with iron deficiency or depletion: clinical and laboratory correlates in 262 non-pregnant adult outpatients. BMC Hematology. 2010;10:9. https://doi.org/10.1186/1471-2326-10-9.

14. Dugan SBN. Pica. My OptumHealth.com. 2006 [accessed 20-10-2007]. Available from: http://www.healthatoz.com/healthatoz/Atoz/common/standard/ transform.jsp?requestURl=/healthatoz/Atoz/ency/pica.jsp.

15. Hunter JM. Macroterme geophagy and pregnancy clays in Southern Africa. Journal of Cultural Geography. 1993;4:69-92. https://doi. org/10.1080/08873639309478381.

16. Vermeer DE, Frate DA A. Geophagia in rural Mississippi: environmental and cultural contexts and nutritional implications. The American Journal of Clinica Nutrition. 1979;32(10):2129-2135. https://doi.org/10.1093/ajcn/32.10.2129. 
17. Ziegler JL. Geophagy: A vestige of paleonutrition? Tropical Medicine and International Health. 1997;2(7):609-611. https://doi. org/10.1046/j.1365-3156.1997.d01-359.x.

18. Boyle JS, Mackay MC. Pica: Sorting it out. Journal of Transcultural Nursing. 1999;10(1):65-68. https://doi.org/10.1177/104365969901000116.

19. Mahaney WC, Watts DP, Hancock RGV. Geophagia by mountain gorillas (Gorilla gorilla beringei) in the Virunga Mountains, Rwanda. Primates. 1990;31:113-120. https://doi.org/10.1007/BF02381034.

20. Reilly C, Henry J. Geophagia: Why do humans consume soil? Nutrition Bulletin. 2000;25:141-144. https://doi.org/10.1046/j.1467-3010.2000.00032.x.

21. Utara S. Chemical analyses of pica soil eaten by the villagers in Sisaket Province. [MSc Unpublished thesis]. Suranaree University of Technology: Thailand; 2002, p. 71.

22. Derman O, Ökstüz-Kanbur N, Yenicesu I, Klink E. Iron deficiency anemia in a group of Turkish adolescents: frequency and contributing factors. International Journal of Adolescent Medicine and Health. 2005;17(2):179-186. https://doi. org/10.1515/IJAMH.2005.17.2.179.

23. Lassmann B, Tsigrelis C, Virk A. 33-year-old woman with marked eosinophilia. Mayo Clinic Proceedings. 2007;82(1):103-106. https://doi.org/10.4065/82.1.103.

24. Al-Rmalli SW, Jenkins RO, Watts MJ, Haris PI. Risk of human exposure to arsenic and other toxic elements from geophagy: trace element analysis of baked clay using inductively coupled plasma mass spectrometry. Environmental Health. 2010;9:79. https://doi.org/10.1186/1476-069X-9-79.

25. Momoh A, Davies TC, Akinsola HA, Iweriabor B, Mashao MB. Geophagy, anaemia and geohelminth infection amongst women in Vhembe District, South Africa. International Journal of Healthcare and Pharmaceutical Research. 2012;1(1):6-10.

26. Bryant BJ, Yau YY, Arceo SM, Hopkins JA, Leitman SF. Ascertainment of iron deficiency and depletion in blood donors through screening questions for pica and restless legs syndrome. Transfusion. 2013;53(8):1637-1644. https://doi. org/10.1111/trf.12061.

27. Raphuthing MV. Association between geophagia and haematological parameters of iron deficiency anaemia in geophagic Qwa-Qwa women [Magister Technologiae thesis]. Free State: Central University of Technology; 2014.

28. Geissler PW, Mwaniki D, Thiong'o F, Friis H. Geophagy as a risk factor for geohelminth infections: a longitudinal study of Kenyan primary school children. Transactions of the Royal Society of Tropical Medicine and Hygiene. 1998,92(1):711. https://doi.org/10.1016/S0035-9203(98)90934-8.

29. Nchito M, Geissler PW, Mubila L, Friis H, Olsen A. Effects of iron and multimicronutrient supplementation on geophagy: a two-by-two factorial study among Zambian schoolchildren in Lusaka. The Royal Society of Tropical Medicine and Hygiene. 2004;98(4):218-227. https://doi.org/10.1016/ S0035-9203(03)00045-2.

30. Kawai K, Saathoff E, Antelman G, Msamanga G, Fawzi WW. Geophagy (soil-eating) in relation to anemia and helminth infection among HIV-infected pregnant women in Tanzania. The American Society of Tropical Medicine and Hygiene. 2009;80(1):36-43. https://doi.org/10.4269/ajtmh.2009.80.36.

31. Njiru H, Elchalal U, Paltiel O. Geophagy during pregnancy in Africa: a literature review. Obstetrical \& Gynecological Survey. 2011;66(7):452-9. https://doi. org/10.1097/OGX.0b013e318232a034.

32. Walker ARP, Walker BF, Sookaria Fl, Cannan RJ. Pica. Journal of the Royal Society of Health. 1997;117(5):280-284. https://doi.org/10.1177 $\% 2$ F146642409711700503.

33. Smith B, Rawlins BG, Cordeiro MJAR, et al. The bioaccessibility of essential and potentially toxic trace elements in tropical soils from Mukono District, Uganda. Journal of the Geological Society. 2000;157(4):885-891. https://doi.org/10.1144/ jgs.157.4.885.

34. De Jager L, Ngole WM, Ekosse GE. Human health aspects related to the ingestion of geophagic clayey soils from Free State and Limpopo provinces. South Africa. Journal of New Generation Science. 2013;11(2):1-18.

35. Von Garnier C, Stünitz H, Decker M, Battegay E, Zeller A. Pica and refractory iron deficiency anaemia: a case report. Journal of Medical Case Reports. 2008;2:324. https://doi.org/10.1186/1752-1947-2-324.

36. Mogongoa LF, Brand CE, De Jager L, Ekosse GE. Haematological and iron status of Qwa Qwa women in South Africa. Medical Technology SA. 2011;25(1):33-37.

37. Kassebaum $N$, Jasrasaria $R$, Naghavi $M$, et al. A systematic analysis of global anemia burden from 1990 to 2010. Blood. 2014;123(5):615-624. https://doi. org/10.1182/blood-2013-06-508325.

38. Hoffbrand AV, Moss PAH. Essential Haematology. 7th ed. Wiley-Blackwell: Oxford, UK; 2016.
39. Worwood M, May A, Bain BJ. Iron deficiency anaemia and iron overload. In: Bain BJ, Bates I, Laffan MA, editors. Dacie and Lewis: Practical Haematology. 12th ed. Philadelphia: Churchill Livingstone-Elsevier; 2017. p. 165-186. https://doi. org/10.1016/B978-0-7020-6696-2.00009-6.

40. De Benoist B, McLean E, Egli I, Cogswell M. Worldwide prevalence of anaemia 1993-2005. WHO Global Database on Anaemia Geneva, World Health Organization; 2008. p. 1-35.

41. Kruger M, Dhansay A, Van Staden E, et al. Anaemia and iron deficiency in women in the third trimester of pregnancy receiving selective iron supplementation. South African Journal of Food Science and Nutrition. 1994;6:132-137.

42. Lawrie D, Coetzee LM, Glencross DK. Iron deficiency anaemia in healthy South African women despite iron fortification. South African Medical Journal. 2008;98(8):606-607.

43. Shisana O, Labadarios D, Rehle T, et al. South Afican National Health and Nutrition Examination Survey (SANHANES-1). Cape Town: HSRC Press; 2013.

44. Phatlhane DV, Zemlin $A E$, Matsha $T E$, et al. The iron status of healthy South African adult population. Clinica Chimica Acta. 2016;460:240-245. https://doi. org/10.1016/j.cca.2016.06.019.

45. Auerbach $M$, Adamson JW. How we diagnose and treat iron deficiency anemia. American Journal of Hematology. 2016;91:31-38. https://doi.org/10.1002/ ajh.24201.

46. Bruner AB, Joffe A, Duggan AK, Casella JF, Brandt J. Randomised study of cognitive effects of iron supplementation in non-anaemic iron-deficient adolescent girls. Lancet. 1996;348(9033):992-996. https://doi.org/10.1016/ S0140-6736(96)02341-0.

47. Chavarro JE, Rich-Edwards JW, Rosner BA, Willett WC. Iron intake and risk of ovulatory infertility. Obstetrics and Gynecology. 2006;108(5):1145-1152. https:// doi.org/10.1097/01.AOG.0000238333.37423.ab.

48. Lozoff B, Jimenez E, Smith JB. Double burden of iron deficiency in infancy and low socioeconomic status: a longitudinal analysis of cognitive test scores to age 19 years. Archives of Pediatric and Adolescent Medicine. 2006;160(11):11081113. https://doi.org/10.1001/archpedi.160.11.1108.

49. Wells CW, Lewis S, Barton JR, Corbett S. Effects of changes in hemoglobin level on quality of life and cognitive function in inflammatory bowel disease patients. Inflammatory Bowel Disease. 2006;12(2):123-130. https://doi.org/10.1097/01. MIB.0000196646.64615.db.

50. Falkingham $M$, Abdelhamid $A$, Curtis $P$, et al. The effects of oral iron supplementation on cognition in older children and adults: a systematic review and meta-analysis. Nutrition Journal. 2010p;9(1):4. https://doi. org/10.1186/1475-2891-9-4.

51. Allen RP, Auerbach S, Bahrain H, Auerbach M, Earley CJ. The prevalence and impact of restless legs syndrome on patients with iron deficiency anemia. American Journal of Hematology. 2013;88(4):261-264. https://doi.org/10.1002/ ajh.23397.

52. Seid MH, Dahl NV, Lau G, Bernard K, Strauss W. Effect of ferumoxytol on quality of life in iron deficiency anemia from abnormal uterine bleeding Obstetrics and Gynecology. 2014;123(5):181S-182S. https://doi.org/10.1097/01. AOG.0000447200.43420.e9.

53. Camaschella $C$, Hoffbrand AV, Hershko $C$. Iron metabolism, iron deficiency and disorders of haem synthesis. In: Hoffbrand AV, Higgs DR, Keeling DM, Mehta AB, editors. Postgraduate Haematology, 7th ed. UK: Willey-Blackwell; 2016. p. 21-40. https://doi.org/10.1002/9781118853771.ch3.

54. Abrahams PW, Davies TC, Solomon AO, Trow AJ, Wragg J. Human geophagia, calabash chalk and undongo: mineral element nutritional implications. PLoS ONE. 2013;8(1):e53304. https://doi.org/10.1371/journal.pone.0053304.

55. Pebsworth PA, Seim GL, Huffman MA, et al. Soil consumed by Chacma baboons is low in bioavailable iron and high in clay. Journal of Chemical Ecology. 2013;39:447-449. https://doi.org/10.1007/s10886-013-0258-3.

56. Seim GL, Ahn Cl, Bodis MS, et al. Bioavailability of iron in geophagic earths and clay minerals, and their effect on dietary iron absorption using an in vitro digestion/Caco-2 cell model. Food and Function. 2013;4:1263-1270. https://doi. org/10.1007/s10886-013-0258-3.

57. Abrahams PW, Parsons JA. Geophagy in the tropics: an appraisal of three geophagical materials. Environmental Geochemistry and Health. 1997;19 (1):1922. https://doi.org/10.1023/A:1018477817217.

58. Yount K. You don't know dirt. University of Alabama at Birmington; 2005. p. 1-5.

59. Abrahams PW, Follansbee MH, Hunt A, Smith B, Wragg J. Iron nutrition and possible lead toxicity: an appraisal of geophagy undertaken by pregnant women 
of UK Asian communities. Applied Geochemistry. 2006;21:98-108. https://doi. org/10.1016/j.apgeochem.2005.09.015.

60. Ghorbani H. Geophagia, a soil - environmental related disease. International Meeting on Soil Fertility Land Management and Agroclimatology. Turkey; 2008. p. $957-967$.

61. Odilon Kikouama JR, Le Cornec F, Bouttier S, et al. Evaluation of trace elements released by edible clays in physicochemically simulated physiological media. International Journal of Food Sciences and Nutrition. 2009;60(2):130-142. https://doi.org/10.1080/09637480701614956.

62. Kelsey JL, Whittemore AS, Evans AS, Thompson WD. Methods in Observational Epidemiology. 2nd ed. Oxford UK: Oxford University Press; 1996.

63. Jimenez K, Kulnigg-Dabsch S, Gasche C. Management of iron deficiency anaemia. Gastroenterology and Hepatology. 2015;11(4):241-250.

64. FERRIMED ${ }^{\oplus}$ Package Insert.

65. Tolkien Z, Stecher L, Mander AP, Pereira DI, Powel JJ. Ferrous sulfate supplementation causes significant gastrointestinal side-effects in adults: a systematic review and meta-analysis. PLoS ONE. 2015;10(2):e0117383. https:// doi.org/10.1371/journal.pone.0117383.

66. Bregman DB, Morris D, Koch TA, He A, Goodnough LT. Hepcidin levels predict nonreponsiveness to oral iron therapy in patients with iron deficiency anaemia. American Journal of Hematology. 2013;88(2):97-101. https://doi.org/10.1002/ ajh.23354.

67. Khalafallah A, Dennis A, Bates J, et al. A prospective randomized, controlled trail of intravenous versus oral iron for moderate iron deficiency anaemia of pregnancy. Journal of Internal Medicine. 2010;268(3):286-295. https://doi. org/10.1111/j.1365-2796.2010.02251.x.

68. Nakamine A. ABX Pentra user manual (product number: RAB080FA). Montpellier: Horiba group; 2004. p. 2-13.

69. Wu AHB. Analytical techniques and instrumentation. In: Bishop ML, Fody EP and Schoeff $L$, editors. Clinical chemistry principles, procedures, correlation. 5th ed. Philadelphia: Lippincott Williams and Wilkins; 2005. p. 90-123.

70. Bates I. Reference ranges and normal values. In: Bain BJ, Bates I, Laffan MA, editprs. Dacie and Lewis: Practical Haematology. 12th ed. Philadelphia: Churchill Livingstone-Elsivier; 2017. p. 8-17. https://doi.org/10.1016/ B978-0-7020-6696-2.00002-3.

71. Macdougall IC, Bock HA, Carrera F, Eckardt KU, Gaillard C, Van Wyck D, Roubert B, Nolen JG, Roger SD on behalf of the FIND-CKD Study Investigators. FIND-CKD: a randomized trial of intravenous ferric carboxymaltose versus oral iron in patients with chronic kidney disease and iron deficiency anaemia. Nephrology Dialysis Transplant. 2014;29(11):2075-2084. https://doi.org/10.1093/ndt/gfu201.

72. Froessler B, Cocchiaro C, Saadat-Gilani K, Hodyl N, Dekker G. Intravenous iron sucrose versus oral iron ferrous sulfate for antenatal and postpartum iron deficiency anemia: a randomized trial. Journal of Maternal-Fetal and Neonatal Medicine. 2013;26(7):654-659. https://doi.org/10.3109/14767058.2012.746299.

73. Nchito M, Geissler PW, Mubila L, Friis H, Olsen A. The effect of iron and multi-micronutrient supplementation on Ascaris lumbricoides reinfection among Zambian schoolchildren. Transaction of Royal Society of Tropical Medicine and Hygiene. 2009;103(3):229-36. https://doi.org/10.1016/j. trstmh.2008.08.005.
74. Anker SD, Von Haehling S. Iron Deficiency and Anemia in Heart Failure. 2nd ed. Bremen, Germany: UNI-MED Verlag; 2012.

75. Geisser P. Safety and efficacy of iron(III)-hydroxide polymaltose complex. Arzneimittelforschung. 2007;57(6):439-452. https://doi. org/10.1055/s-0031-1296693.

76. Nwafor AO, Maringowitz JO, Clark CC. Reasons pregnant women who attend antenatal care in Mecklenberg hospital eat soil [MMED dissertation]. University of Limpopo; 2008.

77. Msibi AT, Van Onselen A, Siwela M, Chivenge P. The prevalence and practice of geophagia in Mkhanyakude district of KwaZulu-Natal, South Africa [MSc dissertation]. University of KwaZulu-Natal; 2014.

78. Cooper R, Rotimi C, Ataman S, et al. The prevalence of hypertension in seven populations of west African origin. American Journal of Public Health. 1997,87(2):160-8. https://doi.org/10.2105/AJPH.87.2.160.

79. Steyn K, Gaziano TA, Bradshaw D, Laubscher R, Fourie J; the South African Demographic and Health Coordinating Team. Hypertension in South African adults: results from the Demographic and Health Survey, 1998. Journal of Hypertension. 2001;19(10):1717-25. https://doi. org/10.1097/00004872-200110000-00004.

80. Bradshaw D, Pillay-van Wyk V, Laubscher R, et al. Cause of death statistics for South Africa: Challenges and possibilities for improvement. Cape Town. Medical Research Council. 2011 [accessed 30 October 2012]. Available from: www.mrc. ac.za/bod/cause_death_statsSA.pdf.

81. Gómez-Olivé FX, Alix SA, Madex F, Kyobutungik C, Nonterah E, Micklesfield L, Alberts M, Bouayy R, Hazelhurstx S, Debpuur C, Mashinya F, Dikotope, Sorghoyy H, Cook I, Muthurik S, Soox C, Mukomanax F, Agongo G, Wandabwak C, Afolabi S, Odur A, Tintoyy H, Wagner RG, Hareguk T, Wade A, Kahn K, Norris SA, Crowtherkk NJ, Tollman S, Sankohy O, Ramsay M; AWI-Gen and the H3Africa Consortium. Regional and Sex Differences in the Prevalence and Awareness of Hypertension. An H3Africa AWI-Gen Study Across 6 Sites in Sub-Saharan Africa Global Heart. 2017;12(2):81-90. https://doi.org/10.1016/j.gheart.2017.01.007.

82. Bonovas $S$, Fiorino $G$, Allocca $M$, et al. Intravenous versus oral iron for the treatment of anaemia in inflammatory bowel disease. Medicine. 2016;95(2):e2308. https://doi.org/10.1097/MD.0000000000002308.

83. Martin-Malo A, Borchard G, Flühmann B, et al. Differences between intravenous iron products: focus on treatment of iron deficiency in chronic heart failure patients. ESC Heart Failure. 2019;6(2):241-253. https://doi.org/10.1002/ ehf2.12400.

84. Stoffel NU, Zeder C, Brittenham GM, Moretti D, Zimmermann MB. Iron absorption from supplements is greater with alternate day than with consecutive day dosing in iron-deficient anemic women. Haematologica. 2020;105(5):1232-1239. https://doi.org/10.3324/haematol.2019.220830.

85. Van de Wiele TR, Oomen AG, Wragg J, et al. Comparison of five in vitro digestion models to in vivo experimental results: lead bioaccessibility in the human gastrointestinal tract. Journal of Environmental Science and Health. 2007;42(9):1203-1211. https://doi.org/10.1080/10934520701434919.

86. Wragg J, Cave M, Basta N, et al. An inter-laboratory trial of the unified BARGE bioaccessibility method for arsenic, cadmium and lead in soil. Science of the Total Environment. 2011;409(19):4016-4030. https://doi.org/10.1016/j. scitotenv.2011.05.019. 